DOI: 10.20472/IAC.2018.042.024

SAMAN JAVED

Bahria University, Islamabad, Pakistan, Pakistan

HASSAN SHABBIR SHAH

Bahria University, Pakistan

TAQADUS BASHIR

Bahria University, Pakistan

\title{
WORKPLACE OSTRACISM AS A PREDICTOR OF EMPLOYEE PERFORMANCE AND EMPLOYEE TURNOVER- EVIDENCE FROM THE BANKING SECTOR
}

\begin{abstract}
:
Workplace ostracism has been identified as a separate entity from workplace harassment. Practised through banishing the target from a social group and social interaction, workplace ostracism is probable to have negative impact on the employees. Though different from harassment, it is equally destructive when it comes to the workplace environment. It manifests itself in a number of forms not only at individual level but also at the organizational level. This paper aims to explore the effects of ostracism on employee behaviour in terms of their performance and turnover. Testing the study in the banking sector, the results suggest that ostracism adversely affects employee performance. Similarly, the former leads to high turnover trend. Statistical significance has been found in the inverse relationship between workplace ostracism and employee performance; and workplace ostracism and employee turnover. The study makes a significant contribution towards the literature on Workplace Ostracism, as it examines the effect of workplace ostracism on two of the key performance indicators i.e. Performance and Turnover. The study will also provide managers with insight on the construct of ostracism will enlighten them about the costs associated with the presence of ostracism in the workplace in terms of employee performance $\&$ employee turnover.
\end{abstract}

\section{Keywords:}

Workplace Ostracism, Employee Performance, Employee Turnover.

JEL Classification: D23, J24, L20 


\section{Introduction:}

Harassment involves aggressive behavior towards an employee or a group of employees. It can easily be felt and can openly be observed, as it vividly manifests itself within the organization and lets its presence be known. Unlike harassment which is easily visible there is also a certain phenomenon of passive aggressiveness which cannot easily be seen but is present nonetheless. This lesser-known phenomenon is called Ostracism, and if not more, it is equally potent as harassment. In a psychological context ostracism is explained as an act of ignoring or excluding individuals or groups. It is differentiated from social exclusion; ostracism generally requires ignoring or lack of attention in addition to social exclusion. In an organizational context it is referred to as an act of ignoring or excluding co-workers by inhibiting communication to and from them due to either personal or professional reasons and not including them in any organizational activity or process and thus isolating them in the form of individual or group (Williams \& Nida, 2011)

Ostracism is a powerful sociological phenomenon but negative in its nature (Williams \& Nida, 2011). It may not leave any extrinsic mark, but it causes agony that is often felt deeper and tends to last longer than physical injury. It is also more dangerous than harassment (Robinson \& O'Reilly, 2012). Psychologically speaking, ostracism is painful because it threatens fundamental human needs, such as self-esteem and belonging. Neurologically speaking, in ostracism, the brain's dorsal anterior cingulate cortex, which registers physical pain, also feels this mental pain, suggesting a deeper impact of nonphysical actions and reactions on the human psyche than previously thought (Waldeck, Tyndall, \& Chmiel, 2015).

At the workplace, ostracism causes diminishing performance and increasing turnover. These effects in the long run not only adversely affect the organizations performance but also tarnishes its image in the workforce market (Chung \& Yang, 2017).

There is also a concern for "excused negligent behavior" which in its nature is an exploitative weakness in the organization formed by ostracism, in this the employees that are ostracized but are not much affected by it, do not perform according to requirement and when confronted on their sub-par performance the excuse that they were not informed or not helped, thus turning themselves from convict to innocent, and continuing their sub-standard performance with little to no repercussions, as they can blame their accountability away (Gkorezis \& Bellou, 2016). Furthermore, ostracism is also sometimes seen as an affiliate to certain fraudulent malpractices such as but not limited to, covering tracks, making communication bubbles to delay detection and other malpractices which is a real cause of concern for the organization because if these things remain undiagnosed and not intervened they could have cataclysmically devastating after effects that might become uncontrollable afterwards (Liu \& Xia, 2016).

Ostracism has been separated from harassment in terms of identification due to its rather passive nature as compared to the aggressive tones of harassment which does not undermine its if not less than equal adverse effects that it has on both individual and 
the organization in terms of performance and satisfaction. This plays havoc with the organizational workings let alone the individual effects on the employee. The thing that makes it hard to manage or minimize is that unlike harassment which can easily be sensed, ostracism has to be felt and that too very keenly because of its passiveaggressive nature it can be well hidden in the organization. The effects of ostracism on employee performance and employee turnover need to be ascertained due to the importance of these basic measures in any organizations success, failure or survival.

\section{Literature Review:}

\subsection{Workplace Ostracism}

Recently, workplace ostracism has been differentiated from workplace harassment as a separate Counter Productive Workplace Behavior and has been a topic of active research by organizational psychologists, due to its subtle presence, yet devastating effects on workplace environment which manifest themselves as depreciating performance and increased turnover from the organization.

Psychological outcomes of being ostracized by peers has been the topic of most researches in this aspect. Workplace ostracism is also positively related to psychological distress. Neurologically, it is speculated that the phenomenon of ostracism registers itself as the same pattern in the brain as physical pain. Psychologically, it is observed that ostracism is more harmful than harassment because in ostracism the person feels that he is not even worthy of rebuke and this feeling of worthlessness shatters the person's self-image and affects his self-respect. These all are the causes of psychological distress and not only do the symptoms \& side effects manifest themselves in the personal life of the person but also in the professional life (Robinson, O'Reilly \& Wang, 2012).

The digital ball view has been used by many researchers to determine the effects of ostracism on an individual (Williams, 2001). The digital ball is a sort of a computer game simulation in which there are three participants and only two of them are playing i.e. ball tossing with each other while completely ignoring the third person. Being ignored, it was expected that the third participant will not involve himself with the two already playing thus exiling himself either mentally or physically from the simulation. The digital ball experiment provides much insight on this whole concept of alienation, shunning and ostracism. Williams (2001) deduced that alienation has "intense and genuinely reliable impacts" (p. 140): The ostracized participants reported the high aversive effects that were felt by them during the whole simulation, which were negativity, abandonment, worthlessness, and invisibility in social situations. In normal circumstance the participants expressed feeling some positivity, sense of belongingness, confidence, presence, and control before being subjected to the simulation. (Ruggieri, Bendixen, Gabriel, and Alsaker, 2013a, 2013b; Sebastian, Blakemore, and Charman, 2009).

Ostracism in a workplace takes place when an individual or a group or both (the source) ignores or rejects another member of the organization irrespective of the hierarchical position (the objective) (Robinson, O'Reilly, and Wang, 2012). It includes such activities 
as exclusion from activities and minimal eye contact, alienating the victim, avoidance, cold shoulder, et cetera (Leung, Wu, Chen \& Young, 2011). Workplace ostracism effectively affects specialists and hierarchical processes. Hitlan and Noel (2009) researched the effects of work environment avoidance on counterproductive work environment behavior (CWB), and concluded that avoiding to give and receive supervision is related to hierarchical counter workplace behavior and avoiding peers or alienating peers is was related to relational counter workplace behavior.

As suggested by Quade, Greenbaum and Petrenko (2016), it is also observed that ostracism is also used by dishonest employees to cover or hide their negligence or dishonesty. Furthermore, it leads to grouping of dishonest employees which get more powerful in performing their malpractices and getting off easy. They ostracize the people that can be a source of report to the authorities whilst performing their unethical behavior under the radar. This causes dual damage to an organization.

As per the research of Waldeck, Tyndall and Chmiel, (2015) ostracism results in either miscommunication or lack of communication caused by the insecurity of the targeted person. Ostracism also affects the knowledge capital of an organization due to a feeling of non-relatability with the organization due to isolation and alienation. This happens when the distinct employees are ostracized by the average ones due to their higher performance, possibly leading to brain drain (Gkorezis, Panagiotou \& Theodorou, 2016).

Ostracism not only effects the person's professional life but also his family life. An employee facing ostracism will probably take this effect home (Liu, Kwan, Lee \& Hui, 2013). Similarly, Ferris, Brown, Berry and Lian (2008) discovered that belongingness, confidence, control, and significant presence were all inversely related to shunning and isolation.

\subsection{Employee Performance}

Organizational performance and Employee Performance are two different measures of performance in organizations (Otley, 1999). Organizational performance is wholly dependent upon employee performance and other environmental variables. The difference between organisational and employee performance is that the former represents the performance of the whole organization taking account for all the individual job performances of employees; whereas the latter is the measure of an employee's individual job performance (Hunter, 1986).

Employee performance depends on a plethora of factors ranging from intrinsic to extrinsic factors. It is the most volatile variable in human resources management due to its sensitivity towards other variables in any study. According to the Sharkie (2010), if entrusted with trust and responsibility employees perform better in his job. Not only that, the employees may also show willingness to perform tasks that are somewhat outside their job description. This is because the employees feel empowered and recognized by their employer which is a good thing in the current scenario of employment in which 
the employees feel vulnerable to exploitation. The removal of this fear and uncertainty results in an increase of performance by the employees.

As suggested by Pousa, Mathieu and Trépanier (2017), managerial coaching has beneficial effects on the frontline employees' performance and adequate coaching can increase the performance of employees. Similarly, Topper (2007) reported that supervisors' attitude and performance has significant effect on an employee's performance.

Psychological capital paired with motivation, positively predicts employee performance (Avey, Nimnicht \& Pigeon (2010). Similarly, psychological well-being has a positive and significant effect on employee job performance in addition to the job and work attitudes of the employees (Robertson, Birch \& Cooper, 2012). It was found out that employees who are psychologically positive have better work ethic and job performance and are more motivated. According to Hunter and Hunter (1984) Employee's own abilities especially his/her motivation, are very important to high job performance.

Organizations take good care of their high performing employees and listen to their voice and action since organizational Performance depends upon employee performance. Additionally, exceptional employee performance has been linked with positive consumer perception of service quality, while poor employee performance has been linked with customer complaints and brand switching (Stajkovic \& Luthans, 1999; Pfeffer, 1994).

Furthermore, employee performance is the measure of the wellness of the execution of tasks expected of the employee by the organization. Annual, bi annual and quarterly performance reviews need to be performed in order to track employee performance and in turn track organizational performance as a whole, which will help in finding out any issues in performance. Usually, quantity of output, quality of output, timeliness of output, presence at work and cooperativeness are included in the measures of employee performance (Güngör, 2011). Deadrick and Gardner (1997) point out that the record of outcomes achieved, for each job function, during a specified period of time can be termed as a performance standard. Thus, performance is the distribution of outcomes achieved, and performance that are measured by utilizing a variety of parameters which describe employee performance over the course of time.

\subsection{Employee Turnover}

When members of an organization are replaced by new personnel then turnover is said to have occurred (Carley, 1992). George and Jones (1996) supports employees permanent leaving of the organization is turnover. In simple words, quitting any organization due to any cause whether intrinsic or extrinsic is termed as employee turnover. It is undesirable for an organization to have high turnover rates because it raises costs, causes operational inefficiencies may even lead to losses.

Armstrong (2012) defined turnover as the rate of people leaving an organization and labelled it destructive to the organization. (Griffeth and Hom 2001) defined turnover's three dimensions of effect they are voluntary, involuntary and dysfunctional turnover. 
The turnover initiated by the employee is voluntary turnover while the turnover initiated by the organization is involuntary turnover due to poor performance or organisation restructuring. When hardworking top performers leave the organization due to conflict or dissatisfaction then it is termed as Dysfunctional Turnover. Due to the fact that employees have to retire, move onto another organisation, or leave for other reasons such as ill health, death, and personal reasons amongst others, a low rate of turnover is unavoidable and natural. (Allen, Bryant and Vardaman 2010). Low rate of turnover is not a cause of concern for the employer unlike high rates of employee turnover which are undesirable for both employer and employee. Branham (2005) suggested that there are seven main reasons why employees leave a company: "Employees feel the job or workplace is not what they expected. There is a mismatch between the job and person. There is too little coaching and feedback. There are too few growth and advancement opportunities. Employees feel devalued and unrecognised. Employees feel stress from overwork and have a work/life imbalance. There is a loss of trust and confidence in senior leaders".

Tuzun and Kalemci (2012) reports that those employees who receive organizational support have lower intention for turnover unlike the employees who are given no to little organizational support. Furthermore, Jordan and Troth (2011) states that the supervisor-subordinate exchange also plays a role in reducing turnover.

As stated by Groeneveld (2011), certain intrinsic and extrinsic factors also influence employees to quit the organization. Aspects of the job, the organization, the individual, the labor market and family influences are some factors that that influence turnover in an organization by the employee. The poor morale of any organization is also blamed for causing high turnover (Khatri, Fern and Budhwar, 2001). Gender also plays a role. For instance, women tend to consider intrinsic factors more than men do while contemplating quitting. This is because women tend to have a subjective point of view and are more motivated and concerned about the intrinsic factors of the workplace environment unlike men who tend to have an objective point of view and are motivated and concerned about the extrinsic factors of the workplace environment.

The development of efficient guidelines might prove beneficial against turnover (Allen, Bryant \& Vardaman, 2010). When turnover occurs, it costs the organization not only in terms of recruitment but also in terms of training of new recruits (Mitchell et al, 2001). Like direct costs, indirect costs are also associated with turnover which increase the cost/loss for the organization in the long run (Allen, Bryant \& Vardaman, 2010). Thus, the success of an organization heavily depends upon the implementation and enforcement of HR policies in regard of turnover.

\subsection{Ostracism, Employee Performance and Turnover}

Ostracism results in information delay/gap as a repercussion of the counter productive workplace behavior. When a person or a group is ostracized by other employees, the communication gets halted. This might cause a communication gap thus hindering the transmission of information within the organization. This information bubble is a major cause of performance decrease and a major contributor towards other performance 
indicators i.e. Job Dissatisfaction. Furthermore, not only does it affect employee relations but also raises workplace tensions and provides ground to mismanagement and negligence and in some cases fraud (Gkorezis \& Bellou, 2016).

Liu, Kwan, Lee and Hui (2013) suggest that support from family can lessen the negative effects of ostracism on employee performance by enhancing the employee's ability to cope with feelings of isolation and alienation.

Another one of the side effects of Ostracism is Psychological Distress and low sense of self-worth stemming out of alienation and "cold treatment" by co-workers, thereby leading to decreased work performance and an increased trend towards absenteeism which in turn turns into turnover. (Wu, Yim, Kwan \& Zhang, 2012).

As per the study of Mohammad and Nathan (2008), performance is also linked to turnover i.e. that a good performer will not quit due to his good standing in the organization. However, the low performer will try to jump organizations due to his/her low performance. Poor performers are more likely to quit their jobs even if the organization adjusts them for job satisfaction and turnover intentions, unlike the good performers who when adjusted for job satisfaction were unlikely to leave organization. Implying good performers have little turnover intent (Zimmerman \& Darnold, 2009).

Figure 1: Theoretical Framework

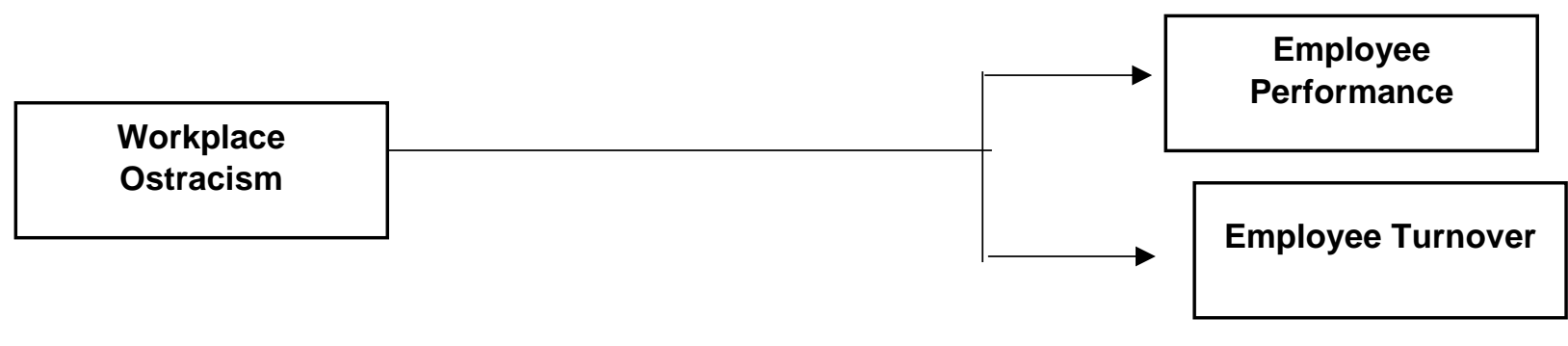

Independent Variable

Dependent Variables

Source: Author made

In the above model, independent variable is the incidence of workplace ostracism and its presence in an organizational work setting. We study the effects of the independent variable (workplace ostracism) on the dependent variables i.e. employee performance and turnover.

\subsection{Hypothesis}

Ho: There is no effect of workplace ostracism on Employee Performance \& Turnover.

$\mathbf{H}_{1}$ : There is effect of workplace ostracism on Employee Performance \& Turnover.

$\mathbf{H}_{2}$ : Workplace ostracism manifests itself as a decrease in Employee Performance.

$\mathbf{H}_{3}$ : Workplace ostracism manifests itself as an increase Employee Turnover. 


\section{Methodology:}

\subsection{Population and Sample}

The population selected for this study are the employees of the banking sector of Pakistan. The study sample consisted of employees of ZTBL Zarai Taraqiati Bank Limited (formerly known as Agricultural Development Bank of Pakistan). Sample Size is around 175 which is selected based on convenience.

\subsection{Scales}

The following scales have been used to elicit the responses from the respondents. Workplace Ostracism is measured adapting 5 items from WOSP scale developed by Wang (2010). Employee Job Turnover Scale from adapted from EEO Staff Exit Questionnaire, comprising of five items. Lastly, Employee Job Performance Scale was adapted from University of Michigan Work Performance Questionnaire, comprising of five items. Five-point Likert scale has been used to elicit the responses.

\section{Data Analysis}

Of the 175 questionnaires distributed only 160 were workable. 7 were returned unsolved and 8 were partially incomplete. So, the response rate was $91.4 \%$ which is acceptable as it is above $90 \%$ implying a high response rate if not maximum.

\subsection{Descriptive Statistics}

The following table shows the descriptive statistics acquired from the data.

Table 1: Descriptives

\begin{tabular}{|c|c|c|c|}
\hline & Variables & Frequency & Percentage \\
\hline \multirow[t]{4}{*}{1} & Gender & & \\
\hline & Male & 115 & 71.9 \\
\hline & Female & 45 & 28.1 \\
\hline & Total & 160 & 100 \\
\hline \multirow[t]{7}{*}{2} & Age & & \\
\hline & $21-25$ & 21 & 13.1 \\
\hline & $26-30$ & 35 & 21.9 \\
\hline & $31-35$ & 52 & 32.5 \\
\hline & $36-40$ & 49 & 30.6 \\
\hline & $>40$ & 2 & 1.3 \\
\hline & Total & 160 & 100 \\
\hline \multirow[t]{5}{*}{3} & Education & & \\
\hline & Bachelor & 98 & 61.3 \\
\hline & Master & 60 & 37.5 \\
\hline & Postgraduate & 2 & 1.3 \\
\hline & Total & 160 & 100 \\
\hline \multirow[t]{5}{*}{4} & Experience & & \\
\hline & $1-10$ & 47 & 29.3 \\
\hline & $11-20$ & 84 & 52.5 \\
\hline & $21-30$ & 29 & 18.2 \\
\hline & Total & 160 & 100 \\
\hline \multirow[t]{3}{*}{5} & Designation & & \\
\hline & Officer & 24 & 15 \\
\hline & Associate & 53 & 33.1 \\
\hline
\end{tabular}




\begin{tabular}{|l|l|c|c|}
\hline Manager & 31 & 19.4 \\
\hline & Assistant Manager & 25 & 15.6 \\
\hline Senior Manager & 13 & 8.1 \\
\hline Executive & 6 & 3.8 \\
\hline Director Total & 7 & 4.4 \\
\hline \multicolumn{2}{|c|}{160} & 100 \\
\hline
\end{tabular}

\subsection{Reliability Analysis of the Study}

Following table shows the values of Cronbach alpha coefficient. Being higher than 0.8, the reliability of all three scales is quite adequate and reliable.

\section{Table 2: Reliabilities}

\begin{tabular}{|l|c|c|}
\hline \multicolumn{1}{|c|}{ Variable } & Number of Items & Cronbach's Alpha \\
\hline Workplace Ostracism & 5 & 0.906 \\
\hline Employee Performance & 5 & 0.862 \\
\hline Employee Turnover & 5 & 0.826 \\
\hline
\end{tabular}

\subsection{Correlations}

The following correlations table signifies the correlations between the independent and dependent variables.

Table 3: Correlations

\begin{tabular}{|c|c|c|c|c|}
\hline \multicolumn{2}{|c|}{ Variables } & $\begin{array}{l}\text { Workplace } \\
\text { Ostracism } \\
\end{array}$ & $\begin{array}{c}\text { Employee } \\
\text { Performance } \\
\end{array}$ & $\begin{array}{c}\text { Employee } \\
\text { Turnover }\end{array}$ \\
\hline Workplace Ostracism & $\begin{array}{l}\text { Pearson Correlation } \\
\text { Sig. (2-tailed) } \\
\text { N }\end{array}$ & $\begin{array}{r}1 \\
160\end{array}$ & $\begin{array}{r}-0.747^{*} \\
0.000 \\
160\end{array}$ & $\begin{array}{r}0.879^{-*} \\
0.000 \\
160\end{array}$ \\
\hline Employee Performance & $\begin{array}{l}\text { Pearson Correlation } \\
\text { Sig. (2-tailed) } \\
\text { N }\end{array}$ & $\begin{array}{r}-0.747^{\circ} \\
0.000 \\
160 \\
\end{array}$ & $\begin{array}{r}1 \\
160 \\
\end{array}$ & $\begin{array}{r}-0.687^{*} \\
0.000 \\
160 \\
\end{array}$ \\
\hline Employee Turnover & $\begin{array}{l}\text { Pearson Correlation } \\
\text { Sig. (2-tailed) } \\
\text { N }\end{array}$ & $\begin{array}{r}0.879^{-} \\
0.000 \\
160\end{array}$ & $\begin{array}{r}-0.687^{*} \\
0.000 \\
160\end{array}$ & $\begin{array}{r}1 \\
160\end{array}$ \\
\hline
\end{tabular}

According to the correlation table, workplace ostracism has a value of -0.747 when correlated with employee performance implying that there is a significantly strong but inverse relationship between workplace ostracism and employee performance i.e. with the increase of workplace ostracism the employee performance gets decreased. Workplace ostracism has a value of 0.879 when correlated with employee turnover implying that there is a significantly strong direct relationship between workplace ostracism and employee turnover i.e. with the increase of workplace ostracism the employee turnover trend gets increased too

This proves the null hypothesis $\left(\mathrm{H}_{0}\right)$ wrong and proves all the other hypotheses $\left(\mathrm{H}_{1}, \mathrm{H}_{2}\right.$ $\& \mathrm{H}_{3}$ ) correct that workplace ostracism does has effect on employee performance and employee turnover but also manifests itself as an increase in the turnover trend of 
employees and decline in performance levels of employees in an organization. Thus, answering the first two research questions and satisfying the first research objective.

\subsection{Regression Analysis}

the following table shows the value of R-square, depicting the change, the predictor variable brings in the criterion variables.

\section{Table 4: Regression}

\begin{tabular}{|c|c|c|c|c|}
\hline Model & $\mathbf{R}$ & $\mathbf{R}^{\mathbf{2}}$ & Adjusted $\mathbf{R}^{\mathbf{2}}$ & Sig \\
\hline $1(\mathrm{EP})$ & 0.173 & 0.03 & 0.028 & 0.027 \\
\hline $2(\mathrm{ET})$ & 0.223 & 0.05 & 0.047 & 0.037 \\
\hline
\end{tabular}

The value of $R^{2}$ in model 1 is 0.030 which means that only $3 \%$ change in Employee Performance is because of workplace ostracism. This means that 1 unit of change in workplace ostracism brings 0.030 units change in employee performance. i.e. $3 \%$ decrease in Employee Performance is explainable through Workplace Ostracism. The value of significance is 0.027 which is less than 0.05 thus implying that the regression model is significant.

Similarly, in model 2, the value of $\mathrm{R}^{2}$ is 0.05 which means that only $5 \%$ change in Employee Turnover is because of workplace ostracism. This means that 1 unit of change in workplace ostracism brings 0.050 units change in employee turnover. i.e. 5 $\%$ increase in Employee Turnover is explainable through Workplace Ostracism. The value of significance is 0.037 which is less than 0.05 thus implying that the regression model is significant.

The results obtained from the statistical analysis conclude that ostracism leads to decreased employee performance, while it increases the turnover trend thus proving the null hypothesis wrong and the $1^{\text {st }}$ hypothesis right. The reasons being that ostracism inhibits the communication flow of the organizational performance information to and from the affected employee thus exponentially decreasing the performance. An inversely proportional relationship is established between Workplace Ostracism and Employee Performance i.e. As the ostracism in the workplace rises, the employee performance decreases This proves the second hypothesis right.

Similarly, results show a positive effect of ostracism on workplace turnover. As the ostracism in the workplace increases the employee turnover trend also increases. The reasons being that when the employees are exposed to ostracism, they start to feel uncomfortable and their overall perception, if remains unaddressed or unnoticed leads to workplace turnover. Ostracism not only leads to poorer performance but also affects the social context of the organization in which if the worker feels like an outcast he will move to another organization. This proves the third hypothesis right. 


\section{Discussion:}

Workplace ostracism is an adverse workplace behaviour. It affects not only individual, but also the organization as a whole in two ways. First, it deteriorates the employee performance and second, it increases the turnover trend. Both these effects are detrimental for the organization. Thus, ostracism is a major concern for the employers because this hidden culprit is the cause of many undesired outcomes that includes diminishing performance and a raised rate of turnover from the organization.

Workplace ostracism differs from Workplace harassment. The former is a passiveaggressive behavior while the latter is an aggressive behavior; due to which ostracism can sometimes not be actively seen by the managers of the organization but can easily felt by the employees or peers. Based on previous findings, it is easily deducible that workplace ostracism has similar consequences like that of workplace harassment at an organizational level. However, at the individual level, consequences of ostracism were direr. This makes ostracism an important variable for empirical research.

The study chose two dependent variables. Firstly, employee performance is one of the vital yardsticks of how effectively organization is functioning. According to Peng and Zeng (2017), the presence of workplace ostracism in a workplace results in performance decrease due to the counterproductive work behavior caused by alienation. Similarly, performance is also tied to turnover. Generally speaking low performance can make people to quit their jobs. Performance is bound to certain contexts and scenarios. Though, it is not always the case, it does increase employee's ability to seek and get a job somewhere else.

The basic unit of performance in any organization is the people. Organization can not survive and thrive without its people. Healthy organizations retain their good performers and avoid turnover. Not only high turnover is destructive in terms of cost but it also compromises organization's reputation in the form of brain drain, recurrent hiring problems and escalating training and replacement costs. When ostracized employees engage less in organizational citizenship behaviors due to the lacking in their organizational identification which is a result of deprecation in their self-worth. This not only results in higher turnover rates for the organization but also a significant decrease in performance (Wu, Liu, Kwan \& Lee, 2015).

\section{Directions for Future Researches}

Future studies should take into account the moderating and mediating effects of different variables on the relationship. It is inferred that employee's job satisfaction can have moderating effects upon employee turnover, employee absenteeism can be used as mediator for the observed relationship. Also, other additional variables can be considered as dependent variables such as organizational citizenship behavior, employee psychological contract and other employee-oriented variables. Ostracism can be expanded into its different constituents. The study was carried out in an economically unstable country thus having certain psychological influences among the population in accordance with the prevalent conditions, research in another country having economic 
stability might yield different results. The sample taken for the sake of convenience was from the public sector, taking sample from the private sector might give different results. Increasing the sample size further is also suggestable when considering future research. These researches can provide better insight on the whole workplace ostracism phenomenon and help organizations to timely nip it in the bud so that it does not adversely affect performance and turnover.

\section{References:}

ALLEN, D.G., BRYANT, P.C. and VARDAMAN, J.M. (2010). Retaining Talent: Replacing Misconceptions with Evidence-Based Strategies. Academy of Management Perspectives, 2010, Vol. 24, No. 2, pp. 48-64. Academy of Management.

ARMSTRONG, M. (2012). A Handbook of Human Resource Management Practice. London: Kogan Page.

AVEY, J.B., NIMNICHT, J. L. and PIGEON, N.G. (2010). Two Field Studies Examining The Association Between Positive Psychological Capital And Employee Performance. Leadership \& Organization Development Journal, 2010, Vol 31, No. 5, pp. 384-401. Emerald Group Publishing Limited.

BRANHAM, L. (2005). The 7 Hidden Reasons Employees Leave. American Management Association.

CARLEY, K. (1992). Organizational Learning and Personnel Turnover. Organization Science, 1992, Vol. 3, No. 1, pp. 20-46. JSTOR.

CHUNG, Y.W. and YANG, J.Y. (2017). The Mediating Effects of Organization-Based Self-Esteem for The Relationship Between Workplace Ostracism and Workplace Behaviors. Baltic Journal of Management, 2017, Vol. 12, No. 2, pp. 255-270. Emerald Group Publishing Limited.

DEADRICK, D.L. and GARDNER, D.G. (1997). Distributional Ratings of Performance Levels and Variability- An Examination of Rating Validity in a Field Setting. Group and Organization Management, 1997, Vol 22, No. 3, pp. 317-342. Sage Journals.

FERRIS, D. L., BROWN, D. J., BERRY, J. W., and LIAN, H. (2008). The Development and Validation of the Workplace Ostracism Scale. Journal of Applied Psychology, 2008, Vol 93, No. 6, pp. 13481366. American Psychological Association.

GEORGE, J.M. and JONES, G.R. (1996). The Experience of Work and Turnover Intentions: Interactive Effects of Value Attainment, Job Satisfaction, and Positive Mood. Journal of Applied Psychology, 1996, Vol. 81, No. 3, pp. 318-325. American Psychological Association.

GKOREZIS, P. and BELLOU, V. (2016). The Relationship Between Workplace Ostracism And Information Exchange- The Mediating Role of Self-Serving Behavior. Management Decision, 2016, Vol. 54, No. 3, pp. 700-713. Emerald Group Publishing Limited.

GKOREZIS, P., PANAGIOTOU, M. and THEODOROU, M. (2016). Workplace Ostracism and Employee Silence in Nursing: The Mediating Role of Organizational Identification. Journal of Advanced Nursing, 2016, Vol 72, No 10, pp. 2381-2388. Wiley Online Library.

GRIFFETH, R.W., and HOM, P.W. (2001). Retaining Valued Employees. Thousand Oaks, CA: Sage.

GROENEVELD, S. (2011). Diversity and Employee Turnover In The Dutch Public Sector: Does Diversity Management. International Journal of Public Sector Management, 2011, Vol 24, No. 6, pp. 594612. Emerald Group Publishing Limited

GÜNGÖR, P. (2011). The Relationship between Reward Management System and Employee Performance with the Mediating Role of Motivation: A Quantitative Study on Global Banks. Procedia- Social and Behavioral Sciences, 2011, Vol 24, pp. 1510-1520. Elsevier. 
HITLAN, R. T., and NOEL, J. (2009). The Influence of Workplace Exclusion and Personality on Counterproductive Work Behaviours: An Interactionist Perspective. European Journal of Work and Organizational Psychology, 2009, Vol 18, No. 4, pp. 477-502. Taylor \& Francis.

HUNTER, J. E. (1986). Cognitive Ability, Cognitive Aptitudes, Job Knowledge, and Job Performance. Journal of Vocational Behavior, 1986, Vol 29, No. 3, pp. 340-362. Elsevier.

HUNTER, J.E. and HUNTER, R.F. (1984). Validity and Utility of Alternative Predictors of Job Performance. Psychological Bulletin, 1984, Vol 96, No. 1, pp. 72-98. American Psychological Association.

JORDAN, P. J. and TROTH, A. (2011). Emotional Intelligence and Leader Member Exchange: The Relationship with Employee Turnover Intentions and Job Satisfaction. Leadership \& Organization Development Journal, 2011, Vol 32, No. 3, pp. 260-280. Emerald Group Publishing Limited.

KHATRI, N., FERN, C.T. and BUDHWAR, P. (2001). Explaining employee turnover in an Asian context. Human Resource Management Journal, 2001, Vol. 11, No. 1, pp. 54-74. Wiley Online Library.

LEUNG, A. S., WU, L., CHEN, Y., and YOUNG, M. N. (2011). The Impact of Workplace Ostracism in Service Organizations. International Journal of Hospitality Management, 2011, Vol 30, No. 4, pp. 836-844. Elsevier.

LIU, J., KWAN, H. K., LEE, C. and HUI, C. (2013). Work-To-Family Spillover Effects Of Workplace Ostracism: The Role Of Work Home Segmentation Preferences. Human Resource Management, 2013, Vol 52, No. 1, pp. 75-93. Wiley Periodicals Inc.

LIU, H. and XIA, H. (2016). Workplace Ostracism: A Review and Directions for Future Research. Journal of Human Resource and Sustainability Studies, 2016, Vol 4, No. 3, pp. 197-201.

MITCHELL, T.R., HOLTOM, B.C., LEE, T.W., SABLYNSKI, C.J. and EREZ, M. (2001). Why People Stay: Using Job Embeddedness to Predict Voluntary Turnover. The Academy of Management Journal, 2001, Vol. 44, No. 6, pp. 1102-1121. Academy of Management.

MUHAMMAD, E. and NATHAN, S. (2008). Antecedents and consequences of financial analyst turnover. Review of Accounting and Finance, 2008, Vol 7, No. 4, pp. 355-371. Emerald Group Publishing Limited.

OTLEY, D. (1999). Performance Management: A Framework for Management Control Systems Research. Management Accounting Research, 1999, Vol 10, No. 4, pp. 363-382. Elsevier.

PENG, A.C. and ZENG, W. (2017). Workplace Ostracism and Deviant and Helping Behaviors: The Moderating Role of 360 Degree Feedback. Journal of Organizational Behavior, 2017, Vol 38, No. 6, pp. 833-855. Wiley Online Library.

PFEFFER, J. (1994). Competitive Advantage through People: Unleashing the Power of the Workforce. Harvard Business School Press.

POUSA, C., MATHIEU, A. and TREPANIER, C. (2017). Managing Frontline Employee Performance Through Coaching: Does Selling Experience Matter? International Journal of Bank Marketing, 2017, Vol 35, No. 2, pp. 220-240. Emerald Group Publishing Limited.

QUADE, M.J., GREENBAUM, R. L. and PETRENKO, O.V. (2016). "I Don't Want To Be Near You, Unless ... ": The Interactive Effect Of Unethical Behavior And Performance Onto Relationship Conflict And Workplace Ostracism. Personnel Psychology, 2016, Vol 70, No. 3, pp. 675-709. Wiley Online Library.

ROBERTSON, I.J., BIRCH, A.J. and COOPER, C.L. (2012). Job And Work Attitudes, Engagement And Employee Performance: Where Does Psychological Well-Being Fit In? Leadership \& Organization Development Journal, 2012, Vol 33, No. 3, pp. 224-232. Emerald Group Publishing Limited. 
ROBINSON, S. L., O'REILLY, J., and WANG, W. (2012). Invisible at Work: An Integrated Model of Workplace Ostracism. Journal of Management, 2013, Vol 39, No. 1, pp. 203-231. Sage Publications.

RUGGIERI, S., BENDIXEN, M., GABRIEL, U., and ALSAKER, F. (2013a). Cyberball: The Impact of Ostracism on The Well-Being of Early Adolescents. Swiss Journal of Psychology, 2013a, Vol 72, No. 2, pp. 103-109. American Psychological Association.

RUGGIERI, S., BENDIXEN, M., GABRIEL, U., and ALSAKER, F. (2013b). Do Victimization Experiences Accentuate Reactions to Ostracism? An Experiment Using Cyberball. International Journal of Developmental Science, 2013b, Vol 7, No. 1, pp. 25-32.

SEBASTIAN, C., BLAKEMORE, S.J. and CHARMAN, T. (2009). Reactions to Ostracism in Adolescents with Autism Spectrum Conditions. Journal of Autism and Developmental Disorders, 2009, Vol 39, No. 8, pp. 1122-1133. Springer.

SHARKIE, R. (2010). Trust in Leadership is Vital for Employee Performance. Management Research News, 2010, Vol 32, No. 5, pp. 491-498. Emerald Group Publishing Limited.

STAJKOVIC, A.D. \& LUTHANS, F. (1999). The Relative Effects of Different Incentive Motivators on Work Performance. Paper presented at the Academy of Management Meeting, San Diego, CA, 1998.

TOPPER, E. F. (2007). Supervisor's Attitude and Employee's Performance. New Library World, 2007, Vol 108, No. 9/10, pp. 460-462. Emerald Group Publishing Limited.

TUZUN, I. K. and KALEMCI, R.A. (2012). Organizational And Supervisory Support In Relation To Employee Turnover Intentions. Journal of Managerial Psychology, 2012, Vol 27, No. 5, pp. 518534. Emerald Group Publishing Limited.

WALDECK, D., TYNDALL, I. and CHMIEL, N. (2015). Resilience to Ostracism: A Qualitative Inquiry. The Qualitative Report, 2015, Vol 20, No. 10, pp. 1646-1670.

WANG, B. (2014). Dispositional Agreeableness Predicts Ostracizing Others at Work. Dissertation, Michigan State University.

WILLIAMS, K. D. (2001). Ostracism: The Power of Silence. New York: Guilford Press.

WILLIAMS, K.D. and NIDA, S.A. (2011). Ostracism- Consequences and Coping. Current Directions in Psychological Science, 2011, Vol 20, No. 2, pp. 71-75. Sage Journals.

WU, C., LIU, J., KWAN, H.K. \& LEE, C. (2015). Why and When Workplace Ostracism Inhibits Organizational Citizenship Behaviors: An Organizational Identification Perspective. Journal of Applied Psychology, 2016, Vol 101, No. 3, pp. 362-378. American Psychological Association.

WU, L., YIM, F. H., KWAN, H.K. and ZHANG, X. (2012). Coping with Workplace Ostracism: The Roles of Ingratiation and Political Skill in Employee Psychological Distress. Journal of Management Studies, 2012, Vol 49, No. 1, pp. 178-199. Wiley Online Library.

ZIMMERMAN, R.D. AND DARNOLD, T.C. (2009). The Impact of Job Performance on Employee Turnover Intentions and the Voluntary Turnover Process: A Meta-Analysis and Path Model. Personnel Review, 2009, Vol 38, No. 2, pp. 142-158. Emerald Group Publishing Limited. 